\title{
Spray collapse in low-pressure injection systems operating in flash-boiling conditions
}

\author{
Łukasz Jan Kapusta * \\ Faculty of Power and Aeronautical Engineering, Warsaw University of Technology, Warsaw, \\ Poland \\ ${ }^{*}$ Corresponding author email: lukasz.kapusta@pw.edu.pl
}

\begin{abstract}
Flash-boiling sprays formed by initially separated plumes, under a high degree of overheating, may collapse into a single spray cloud; leading to increases in the spray penetration and narrowing of the spray angle. This effect is not only dependent on the degree of overheating, but also on the number of nozzles. It is important to note that these, and most of the other observations related to flashing sprays were made for high-pressure systems. In this study, the spray collapse process is investigated for low injection pressure in order to verify if the effects of the flash boiling on spray formation will be dependent on the number of nozzles, as was observed for high-pressure sprays. For this purpose, the water sprays formed by a commercial six-hole injector were compared with the results obtained for a two-hole injector. The sprays were analysed in terms of global spray structure and global spray parameters, such as the spray penetration and the spray angle. The sprays did show major differences, and both collapsed at the highest considered temperature. However, in the case of the six-hole injector the collapse was noticed also for lower temperatures. Despite the collapse, no considerable increase in penetration was observed in any of the cases.
\end{abstract}

\section{Keywords}

injection, spray, flash boiling, flare flash-boiling, spray collapse

\section{Introduction}

Flash boiling occurs when the temperature of the injected liquid is higher than the boiling point at a given environmental pressure. It has been shown that in such conditions inside the liquid phase vapour bubbles grow rapidly and cause micro-explosions of droplets and ligaments $[1,2]$. The break-up of the droplets induced by the rapid expansion of the bubbles results in smaller droplets and alters the global spray structure. The bursting of the droplets leads to a higher radial-to-axial momentum ratio and consequently, to an increased spray angle. On the other hand, smaller droplets, due to the increased importance of the aerodynamic drag, are less prone to penetrate the gaseous medium, which results in a reduced spray tip penetration [3-6]. The strong flash boiling may result in the merging of the spray plumes into one cloud [7]. When the liquid is superheated even more, the spray behaviour may change again and increased spray penetration can be observed [8]. Zeng et al. [8] distinguished three different spray formation regimes, in which the spray behaviour was different. They linked these regimes with the ambient-to-saturation pressure ratio. In this study, a factor $R_{p}$ defined as the saturation-to-ambient pressure ratio will be used. For $R_{p}$ smaller than 1 , the spray was nonflashing. For the ratio within the range of 1-3.33, the spray penetration was decreasing, and the spray width was increasing with the increasing $R_{p}$ parameter. When the $R_{p}$ was above 3.33, the spray collapsed and formed a single spray cloud. In that regime, with increasing the $R_{p}$ parameter, the spray penetration was increased, and the spray width was decreased [8]. $\mathrm{Xu}$ et al. [9] performed experiments on droplet size reduction by flash boiling for different injection pressures (3-15 MPa). They observed that increasing the $R_{p}$ in the transitional flashboiling regime reduced the droplet size faster for lower injection pressure. In the "flare" flash- 
boiling regime droplet sizing was independent of the preheat temperature. However, the spray structure was influenced with a further increase of the $R_{p}$ parameter. Weber and Leick [10], studied one- and two-hole injectors and noticed that the pressure ratio needed to reach the spray collapse and the "flare" flash-boiling regime, was significantly higher for the two-hole injector than for five- or more-hole injectors. This clearly showed that neither the superheating level, nor the pressure ratio is a universal parameter to characterise flash-boiling sprays, and the other set-up properties are important as well. They linked the spray-collapse effect with the nozzles' separation angle, which for a two-nozzle injector was higher than for the five- or six-nozzle injector. This observation was later confirmed by Lacey et al. [11] for propane and iso-octane sprays formed at an injection pressure of $20 \mathrm{MPa}$. Based on their observation, they developed a criterion for the spray collapse which included the geometrical parameters of the injector as well.

As far as the high-pressure injection systems ( $\geq 5 \mathrm{MPa}$ ) are concerned, it seems clear that the spray collapse depends on the geometrical parameters of the injector. For the low injection pressure systems $(<1 \mathrm{MPa})$, the situation is unclear, as the number of studies carried out at low injection pressure under flash-boiling conditions is limited. Moreover, the different effects of flash boiling on spray parameters for different injection pressures reported for high-pressure systems [9] may suggest that the spray collapse could be also dependent on the injection pressure. The study of Jin et al. [12] on hydrocarbon liquid jets formed at low injection pressures (up to $0.9 \mathrm{MPa}$ ) showed that the discharge coefficient, which was related to the effects of internal cavitation and flash boiling, decreased faster for lower injection pressures. Moreover, at fuel temperatures higher than the boiling point, the spray atomisation was primarily dependent on the $R_{p}$. As for the global spray structure, they noticed that the spray angle increased faster for higher injection pressures. For the temperatures above the boiling point, the spray angle was the lowest for the lowest injection pressure. Larsson et al. [13] studied low-pressure sprays formed by an injector equipped with a heating chamber and two valves (at the inlet and outlet to the chamber) to inject the liquid at its vapour pressure. For the highest considered temperature $\left(190^{\circ} \mathrm{C}\right)$ they observed a threefold reduction of DV10 (tenth percentile of volume distribution) compared to the case with the lowest chamber temperature $\left(130^{\circ} \mathrm{C}\right)$. It is assumed that the temperature effect on the spray formation was combined with the pressure effect, as with an increase of the heating chamber temperature the injection pressure was also increased. As shown by Van Vuuren et al. $[14,15]$ the structure of low-pressure sprays formed under flash-boiling conditions significantly changes compared to the subcooled case. Despite the significant change in the spray structure it is difficult to conclude on the spray collapse, as the injector studied by them was characterised by a low separation angle of the plumes and no void part was clearly distinguishable in the subcooled case. It is clear that flash boiling influences spray formation in low-pressure systems, altering all the spray parameters, and its role is as significant as in high-pressure systems. Nevertheless, the conclusions on spray collapse can be very limited. A recent study on lowpressure sprays formed by a two-hole injector under flash-boiling conditions did show moderate spray collapse, appearing as a merging of the individual plumes to fill an initially void volume between the jets; although, there was no increased spray penetration even for $140{ }^{\circ} \mathrm{C}$, which corresponded to the $R_{p}$ of 3.57 [16]. However, it is unclear if the effects will be similar for a six-hole injector or if the collapse will be stronger (as observed for high-pressure sprays), leading to an increased penetration and decreased spray angle. One could expect a different collapse mechanism in low-pressure systems than in the case of high-pressure sprays, in which, as the simulations suggest, the collapse is driven by the interaction of the shocks in the centre between the plumes $[17,18]$. While in the case of low-pressure sprays formed at $R_{p}<<50$, shocks are not expected [19].

This study is aimed at filling these gaps by providing information on the spray formation from a six-hole injector for the same conditions as previously reported for a two-hole injector [16]. 
In order to make a direct comparison of sprays formed by the two- and six-hole injectors the imaging for a two-hole injector was repeated, so the both injectors were investigated using the same set-up. The spray collapse was investigated qualitatively in terms of spray structure as well as quantitatively by comparing the spray tip penetration and the spray angle.

\section{Experimental Set-up}

In order to characterise the spray collapse of water sprays formed under flash-boiling conditions high-speed imaging was applied. The sprays were illuminated by two halogen lights (500 W each). The camera set-up and thus the field of view, was the same regardless of the injector. The whole experimental set-up showing the injectors' orientations in relation to the camera is presented in Figure 1.

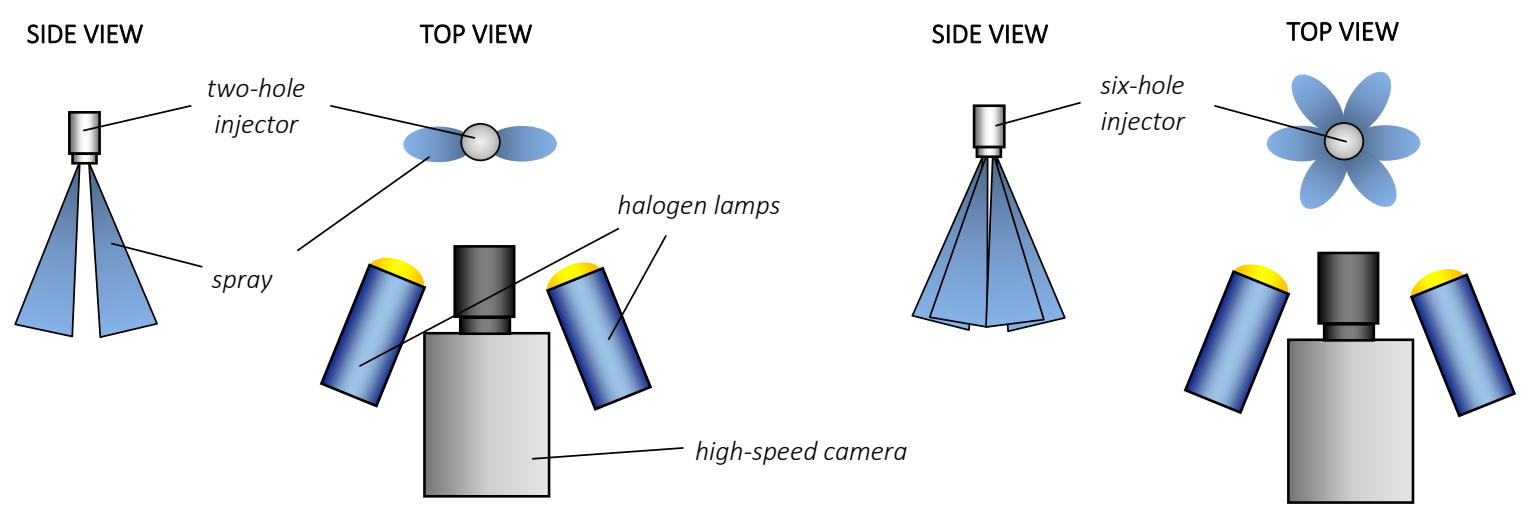

Figure 1. Schematic diagram of the experimental set-up

Two different injectors were used in the study, a two-hole and a six-hole injector (Bosch 0444025030 and 0444025082). The injectors are commercially available and were intended for SCR (selective catalytic reduction) applications. Both injectors had a cooling jacket and were of similar design. The injectors were triggered from the high-speed camera at the start of the recording sequence. The injectors were operated at a pressure of 5 bar (gauge), and the injection duration in all tests was $10 \mathrm{~ms}$. The water tank was pressurised using compressed nitrogen, and the injection pressure was set and monitored using a precise pressure gauge (WIKA CPG1500, measuring range $0-1 \mathrm{MPa}$ gauge, accuracy $0.1 \% \mathrm{FS}$ ). The recording was performed at a frame rate of $10000 \mathrm{fps}$ using a high-speed camera (Photron SA1.1) equipped with a Nikon f $2.885-\mathrm{mm}$ lens. The image resolution was $640 \times 896$ pixels and the spatial resolution was $0.0996 \mathrm{~mm} /$ pix. Image acquisition for a certain measurement point was repeated six times, with a 60 -s break between the injections.

Image processing was performed in LaVision DaVis software (version 8.4) and included a background subtraction, spray background separation and calculation of the spray tip penetration and the spray angle. The background subtraction was based on subtracting a first frame (without a spray) of an image sequence from each raw frame of that sequence. In the resulting images the spray was separated from the background based on the pixel intensity. For the purpose of spray tip penetration determination, the threshold was set to 15 , so the pixels with intensity higher than 15 were treated as the spray, while the rest of them were assumed to be the background. The spray tip penetration was measured in the direction of the injector axis (not of a single plume) in order to compare it directly with flashing sprays where two initially separated plumes formed a single cloud. The spray tip penetration was defined as the distance from the injector tip where $99.9 \%$ of the pixels (above the threshold) were located. For the purpose of the spray angle determination, the threshold value for separation of the spray from the background was set to 30 . The spray angle was then 
calculated based on the side profiles of the spray with the assumption that the sides of the angle go through the nozzles' edges. The images captured $3 \mathrm{~ms}$ ASOI (after start of injection) for two extreme temperatures (for both injectors) after the background subtraction with calculated and marked spray tip penetration and spray angle are shown in Figure 2.

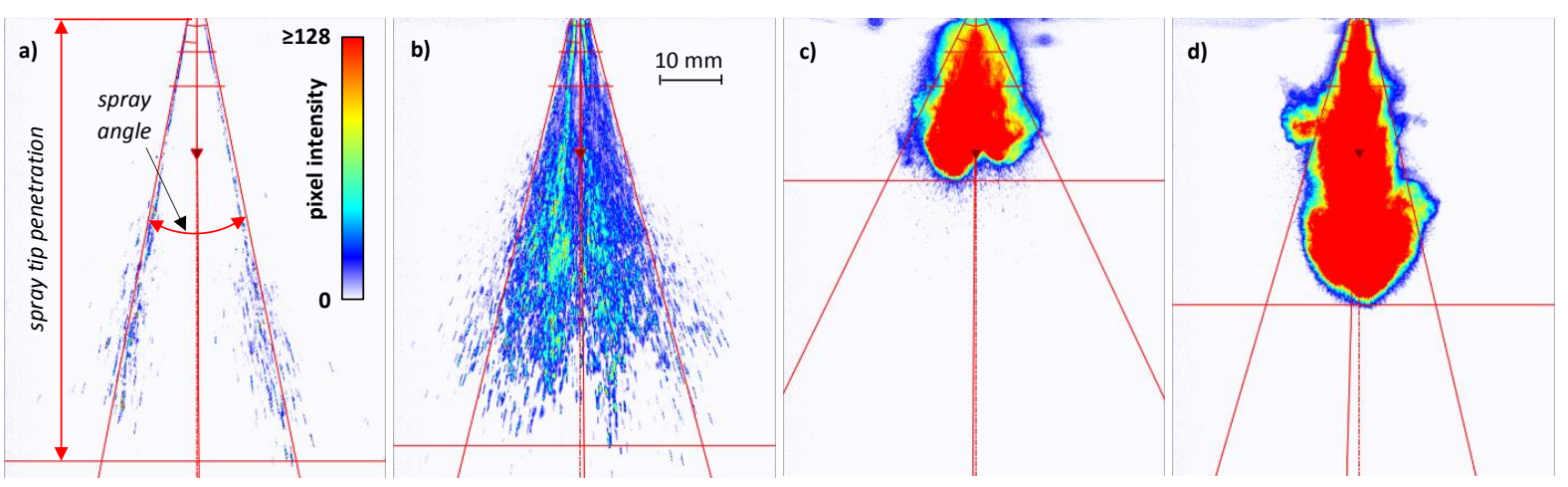

Figure 2. The spray images after the background subtraction with marked spray angle and spray tip penetration $3 \mathrm{~ms}$ ASOI: a) two-hole injector, $60^{\circ} \mathrm{C}$; b) six-hole injector, $60^{\circ} \mathrm{C}$; c) two-hole injector, $150{ }^{\circ} \mathrm{C}$; d) six-hole injector, $150^{\circ} \mathrm{C}$. The colour scale is the same in all images.

The temperature of both injectors was controlled by a coolant circulating in the cooling jackets (integrated to the injectors). The coolant temperature was controlled by a coolant circulator (Huber Kiss K6). The coolant temperature $T_{\text {coolant }}$ was set according to the equation determined in [16] (Equation 1):

$$
T_{\text {coolant }}=4.2631 \times 10^{-4} T_{\text {liquid }}^{2}+1.1691 T_{\text {liquid }}-3.9365
$$

where, $T_{\text {liquid }}$ is the target liquid (water) temperature.

The calculated coolant temperatures required to reach the target temperature of the water are shown in Table 1. Despite the different flow rate of the two- and six-hole injectors, the coolant temperature was set at the same level for both injectors. The tests were based on a single injection event repeated every $60 \mathrm{~s}$, so the higher mass flow rate in the case of the six-hole injector was assumed not to have any effect on the liquid temperature inside the injector.

Table 1. The target water temperatures, together with calculated coolant temperatures

\begin{tabular}{cccc}
\hline$\Delta \mathbf{T} /{ }^{\circ} \mathbf{C}$ & $\begin{array}{c}\text { Saturation-to-ambient } \\
\text { pressure ratio, } \boldsymbol{R p} /-\end{array}$ & $\begin{array}{c}\text { Target water } \\
\text { temperature } /{ }^{\circ} \mathbf{C}\end{array}$ & $\begin{array}{c}\text { Coolant } \\
\text { temperature } /{ }^{\circ} \mathbf{C}\end{array}$ \\
\hline-40 & 0.2 & 60 & 67.7 \\
\hline-20 & 0.47 & 80 & 92.3 \\
\hline-10 & 0.69 & 90 & 104.7 \\
\hline 0 & 1 & 100 & 117.2 \\
\hline 10 & 1.42 & 110 & 129.8 \\
\hline 20 & 1.96 & 120 & 142.5 \\
\hline 30 & 2.67 & 130 & 155.3 \\
\hline 40 & 3.57 & 140 & 168.1 \\
\hline 50 & 4.7 & 150 & 181 \\
\hline
\end{tabular}

The maximum considered target water temperature was $150^{\circ} \mathrm{C}$, which is $10^{\circ} \mathrm{C}$ higher than in the previous study [16]. This was an additional measurement point to increase the saturationto-ambient pressure ratio. There was one more additional measurement point with regards to the previous study $\left(130^{\circ} \mathrm{C}\right)$. Between 120 and $140^{\circ} \mathrm{C}$ there was a change in spray formation from "hybrid-behaviour" to fully-flashing spray [16]. Therefore, this point was assumed to be important in terms of understanding the transition between the spray formation regimes. 


\section{Results and Discussion}

The results did show very different behaviour from the sprays depending on the number of nozzles. Figure 3 shows the instantaneous Mie-scattering images (after background subtraction with applied colour scale) captured $8 \mathrm{~ms}$ ASOI. For comparison purposes and to keep the same ability to visualise larger droplets, which were scattered on the sides of the main cloud, the colour scale for all images was set at the same level. It may be observed that the sprays generated by the two different injectors for the highest temperatures are substantially different. It doesn't mean that the flash boiling occurs differently in two- and sixhole injectors. It may be observed that the images of non-flashing sprays become more intensive at $100^{\circ} \mathrm{C}$. However, no condensing vapour is clearly visible at that point for any of the injectors.

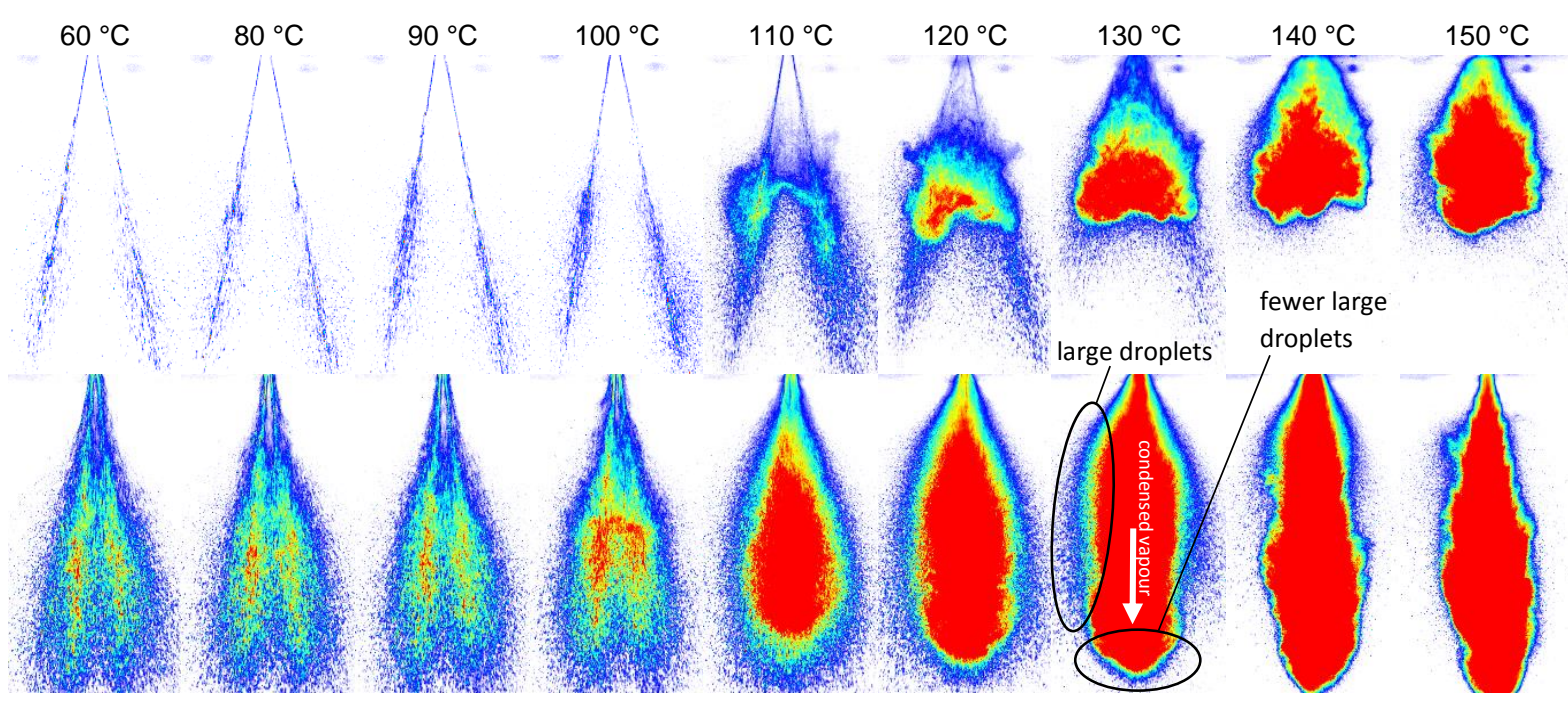

Figure 3. Instantaneous spray images captured 8 ms ASOI: upper row - two-hole injector; lower row - six-hole injector. The colour scale from Figure 2 applies.

When the temperature reaches $110^{\circ} \mathrm{C}$ the cloud of the condensing vapour appears. For the two-hole injector, it can be clearly distinguished from the streams of larger droplets (appearing as distributed spots of the Mie scattering signal). The spray formed by the six-hole injector seems to be a single cloud. However, this effect should be linked to a higher mass flow and thus, a much higher liquid surface, being a source of both a direct scattering signal and water vapour; which then condensates to become an additional source of the Mie scattering signal. The larger droplets are clearly visible near the outer edge of the spray cloud. This means that the flash boiling, understood as flash vaporisation of injected water is similar for both injectors. Nevertheless, the ultimate effect of the flash boiling on the spray formation does depend on the number of nozzles. When the temperature is elevated to $130^{\circ} \mathrm{C}$ the amount of condensed vapour becomes higher. In the case of the two-hole injector, this condensed vapour is concentrated fairly close to the nozzles and does not propagate as far as the larger droplets. In the case of six-hole nozzle injector, the larger droplets are visible as well, but a strong scattering signal with a fairly smooth boundary (between the spray cloud and the surroundings) is observed in the tip of the spray, suggesting a low number of larger droplets. This leads to the conclusion that the condensing vapour, which is generated at the higher rate for the six-hole injector, exits the spray cloud in the tip area leading to a much higher spray penetration than in the case of the two-hole injector. With a further increase of the liquid temperature, the scattering signal from the large droplets is decreased and the border between the spray and the surroundings becomes smoother. This is observed for both injectors. It 
needs to be mentioned that the highest considered temperature $\left(150^{\circ} \mathrm{C}\right)$ was just below the boiling point of water at $0.6 \mathrm{MPa}$ (absolute), which is $158.83^{\circ} \mathrm{C}$ [20]. For this temperature, during some of the injection events (every 2.2 injections) only a vapour was injected. These cases were excluded from the analysis, but it needs to be considered that even the proper injections could be affected by a local pressure drop and internal cavitation.

The spray angle was dependent on time. At the beginning of the spray formation, when the spray clouds were very small, the spray angle couldn't be determined in a reliable way. Therefore, only the results obtained $2 \mathrm{~ms}$ ASOI and later were considered. The spray angle for the example cases is shown in Figure 4.

a)

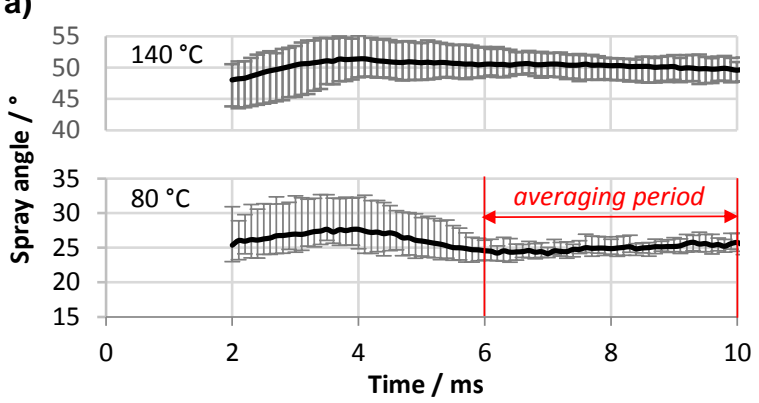

b)

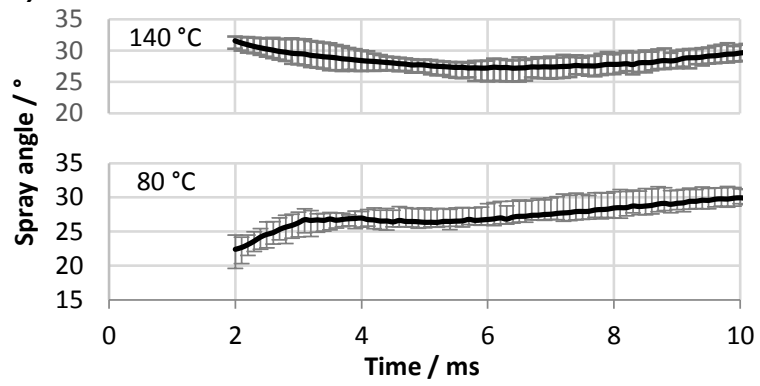

Figure 4. Spray angle - average from six injection events; maximum and minimum values in the series were shown as error bars; a) two-hole injector, b) six-hole injector

To compare the injectors quantitatively, the average spray angle (for six independent injections) was additionally time-averaged between 6 and $10 \mathrm{~ms}$ ASOI. The time-averaged values are shown in Figure 5. It can be observed that for the two-nozzle injector the peak value of the spray angle is achieved for $140^{\circ} \mathrm{C}$, which was the maximum studied temperature previously in [16]. The additional measurement point $\left(150^{\circ} \mathrm{C}\right)$ seems to be the first point at which "flare" flash-boiling develops. However, this observation should be verified for higher injector pressure, to increase the boiling point and reduce the risk of internal cavitation. Regardless of the measurements for $150{ }^{\circ} \mathrm{C}$, the results did show a dependence on the number of nozzles. For the six-hole injector, the peak value of the spray angle is expected to be between 120 and $130{ }^{\circ} \mathrm{C}$; while for the two-nozzle injector, it was $140{ }^{\circ} \mathrm{C}$. An important observation is that the widening of the angle is also different. In the case of the two-nozzle injector the peak widening was more than twofold; while in the case of the six-nozzle injector it was $\sim 30 \%$. It is also important to note that for the six-hole injector the spray angle in the collapsed-spray regime was very similar to that as for the non-flashing spray.

a)

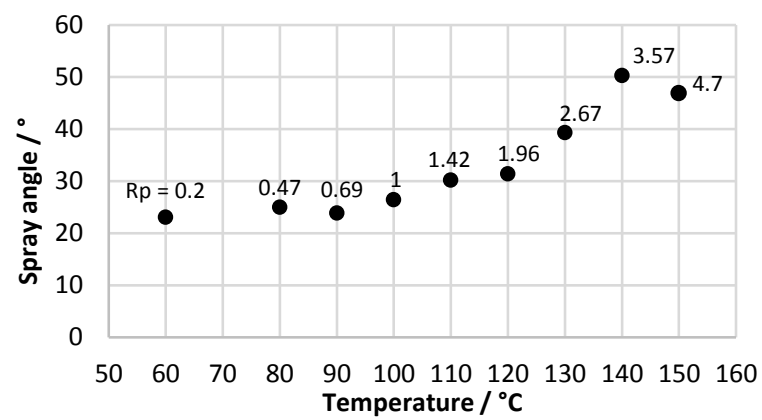

b)

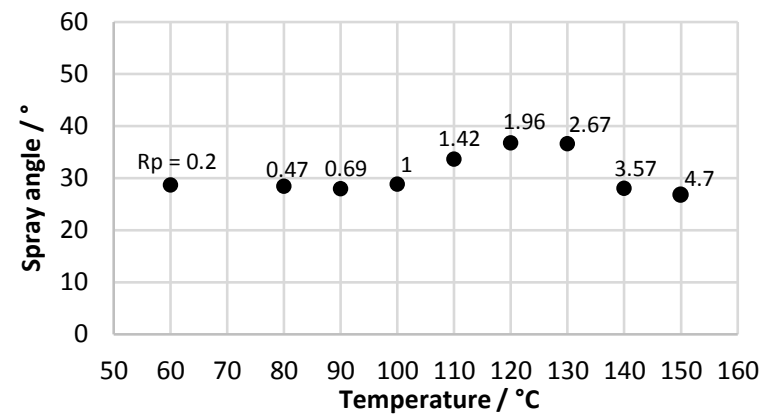

Figure 5. Spray angle, time- and series-averaged values: a) two-hole injector, b) six-hole injector

As for the spray penetration, Figure 3 may suggest that for the six-hole injector it was increased for 140 and $150{ }^{\circ} \mathrm{C}$. The average results for six injections (see Figure 6) do not confirm that. The spray tip penetration for these cases is very similar as for the $130-^{\circ} \mathrm{C}$ case, 
which suggests a minor influence of the temperature (within this range) on the penetration of the spray formed by the six-hole injector. This is very different behaviour from the two-nozzle injector, for which the flash boiling reduced the number of large droplets propagating fast along the nozzles' axes, leading to a decreased spray penetration. For the highest temperature, the spray penetration did increase when compared to the $140{ }^{\circ} \mathrm{C}$ case. However, this change was relatively small and due to the possible influence of in-injector boiling should be confirmed for the higher injection pressures.

a)

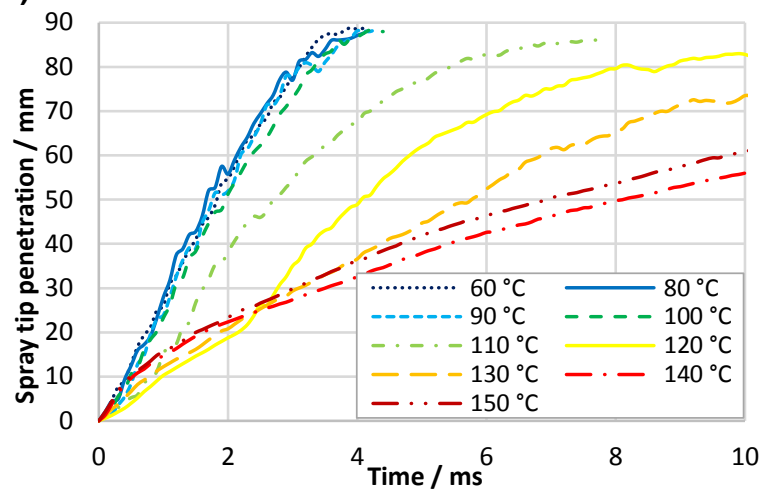

b)

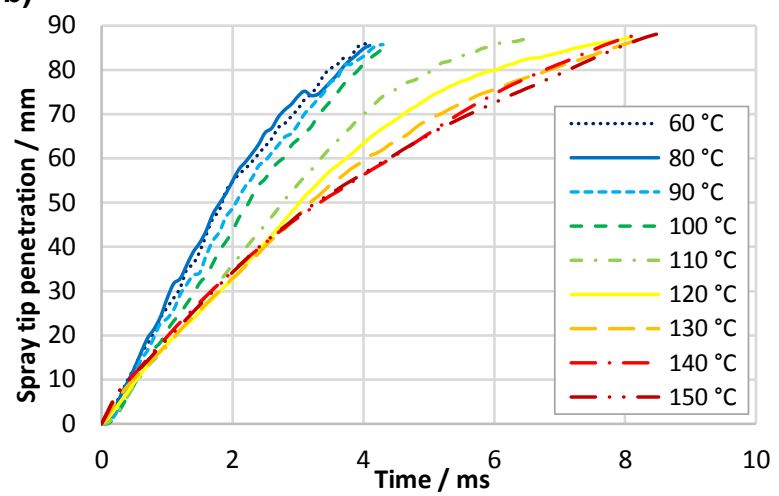

Figure 6. Spray tip penetration - average of six values determined for six different injection events: a) two-hole injector, b) six-hole injector

The quantitative results of the spray angle and spray tip penetration in the flash-boiling regime confirmed very different spray behaviour for the two- and six-hole injectors. The differences according to the qualitative observations of the spray structures, come from the amount of generated water vapour. Moreover, it is expected that the circular pattern of the spray plumes in the six-hole injector forces the air entrainment from the outside of the spray; while due to the large amount of generated vapour, the inner recirculation zone is not present. As a result, the large volume of condensing water vapour propagates along the injector axis.

\section{Conclusions}

This study has confirmed that the spray collapse under flash-boiling conditions in low-pressure injection systems is dependent on the number of nozzles. Both quantitative results (spray angle and spray tip penetration) and global spray structures showed the two- and six-hole injectors behaved very differently; with the six-hole injector generating collapsing sprays at lower temperatures. At the same time, the results suggested that the flash boiling, understood as flash-vaporisation of injected water, occurs in a similar way independently from the number of nozzles. The first signs of condensing vapour and a reduced number of large droplets (appearing as distributed Mie scattering spots) for both injectors were noticed for the same temperatures. Nevertheless, indeed there is a different impact from flash boiling on the spray formation, depending on the number of nozzles. The qualitative observations of the spray structures suggest that this difference comes from the amount of generated vapour, which partially condensates. Additionally, the spray plumes' circular pattern in the six-hole injector is likely to drive the air entrainment from the outside of the spray. While the inner recirculation zone is absent due to the large amount of generated vapour. As a result, the large volume of condensing water vapour propagates along the injector axis. Thus, in the case of the sixnozzle injector, the spray angle is only slightly increased, and the spray penetration is reduced very little when compared with the two-hole injector. Additional experiments based on lightsheet imaging would be beneficial to provide information on the inner region of the collapsed spray cloud, and to confirm this hypothesis. 


\section{Acknowledgments}

This study was funded by the National Science Centre, Poland within the framework of OPUS programme, grant number: 2018/29/B/ST8/01356.

\section{References}

[1] Vanderwege, B. A., 1999, "PhD Thesis - The Effects of Fuel Volatility and Operating Conditions on Sprays from Pressure-Swirl Fuel Injectors," Massachusetts Institute of Technology.

[2] Li, S., Zhang, Y., Qi, W., and Xu, B., 2017, Exp. Therm. Fluid Sci., 80, pp. 305-312.

[3] Vanderwege, B. A., and Hochgreb, S., 1998, Symp. Combust., 27(2), pp. 1865-1871.

[4] Araneo, L., Coghe, A., Brunello, G., and Dondé, R., 2000, SAE Technical Paper 200001-1901.

[5] Zhang, G., Xu, M., Zhang, Y., and Hung, D. L. S., 2013, Proceedings of the FISITA 2012 World Automotive Congress, Springer Berlin Heidelberg, Berlin, Heidelberg, pp. 443454.

[6] Araneo, L., and Donde', R., 2017, Fuel, 191, pp. 500-510.

[7] Montanaro, A., and Allocca, L., 2015, JSAE/SAE 2015 International Powertrains, Fuels \& Lubricants Meeting, SAE International.

[8] Zeng, W., Xu, M., Zhang, G., Zhang, Y., and Cleary, D. J., 2012, Fuel, 95, pp. 287-297.

[9] Xu, M., Zhang, Y., Zeng, W., Zhang, G., and Zhang, M., 2013, SAE Int. J. Fuels Lubr., 6(1), pp. 137-148.

[10] Weber, D., and Leick, P., Sep. 8-10. 2014, ILASS Eur. 26th Annu. Conf. Liq. At. Spray Syst., pp. 8-10.

[11] Lacey, J., Poursadegh, F., Brear, M. J., Gordon, R., Petersen, P., Lakey, C., Butcher, B., and Ryan, S., 2017, Fuel, 200, pp. 345-356.

[12] Jin, Y. I., Lee, H. J., Hwang, K. Y., Park, D. C., and Min, S., 2018, Exp. Therm. Fluid Sci., 90, pp. 200-211.

[13] Larsson, P., Lennard, W., Andersson, O., and Tunestal, P., 2016, SAE Technical Paper 2016-01-2211, SAE International.

[14] van Vuuren, N., Brizi, G., Buitoni, G., Postrioti, L., and Ungaro, C., 2015, SAE 2015 World Congress \& Exhibition, SAE International.

[15] van Vuuren, N., Brizi, G., Buitoni, G., Postrioti, L., and Ungaro, C., 2015, 12th International Conference on Engines \& Vehicles, SAE International.

[16] Kapusta, Ł. J., Rogoz, R., Bachanek, J., Boruc, Ł., and Teodorczyk, A., 2021, SAE Int. J. Adv. Curr. Pract. Mobil., 3(1), pp. 365-377.

[17] Guo, H., Li, Y., Xu, H., Shuai, S., and Zhang, H., 2019, Int. J. Heat Mass Transf., 137, pp. 990-1000.

[18] Gärtner, J. W., Feng, Y., Kronenburg, A., and Stein, O. T., 2021, Fluids, 6(3).

[19] Vieira, M. M., and Simões-Moreira, J. R., 2007, J. Fluid Mech., 572, pp. 121-144.

[20] Linstrom, P. J., and Mallard, G. W., 2001, NIST Chemistry WebBook, NIST Standard Reference Database Number 69, National Institute of Standards and Technology, Gaithersburg MD, 20899. 